\title{
Human milk IgA concentrations during the first year of lactation
}

\author{
Lawrence T Weaver, Helen M L Arthur, James E G Bunn, Julian E Thomas
}

\begin{abstract}
Aims-To measure the concentrations of total IgA in the milk secreted by both breasts, throughout the first year of lactation, in a cohort of Gambian mothers of infants at high risk of infection. Subjects and methods-Sixty five women and their infants were studied monthly from the 4th to 52nd postpartum week. Samples of milk were obtained from each breast by manual expression immediately before the infant was suckled. Milk intakes were measured by test weighing the infants before and after feeds over 12 hour periods; IgA concentrations were determined by enzyme linked immunosorbent assay.

Results-A total of 1590 milk samples was measured. The median (interquartile range) concentration of IgA for all samples was $0.708(0.422-1.105) \mathrm{g} / 1$; that in milk obtained from the left breast was $0.785(0.458-1.247) \mathrm{g} / 1$, and that in milk obtained from the right breast was 0.645 $(0.388-1.011) \mathrm{g} / 1$ ( $\mathrm{p}<0.0001)$. There was no significant change in milk or IgA intakes with advancing infant age, but there was a close concordance of IgA concentrations between the two breasts, with "tracking" of the output of the left and right breasts. There was a significant $(p<0.01)$ negative correlation between maternal age and parity, and weight of milk ingested by infants. During the dry season (December to May) the median (interquartile range) IgA concentration was significantly higher at $0.853(0.571-1.254) \mathrm{g} / 1$ than during the rainy season (June to November), when it was $0.518(0.311-0.909) \mathrm{g} / 1$ (p < 0.0001). Conclusions-Sustained IgA secretion is likely to protect suckling infants from microbial infection.

(Arch Dis Child 1998;78:235-239)
\end{abstract}

Keywords: immunoglobulin A; human milk; lactation

(chartment of Child

Newcastle-upon-Tyne

J E G Bunn

JE Thomas

MRC Dunn Nutrition Unit, Cambridge

L T Weaver

J E G Bunn

JE Thomas

Correspondence to: Professor L T Weaver, Department of Child Health, University of Glasgow, Yorkhill Hospitals, Glasgow G3 8SJ.

Accepted 13 August 1997 pairs of heavy and light chains linked together by secretory component and a J chain. Via the enteromammary circulation a lactating mother may secrete in her milk specific IgA that protects her infant from microbial antigens to which both she and her infant have been exposed. Antigens ingested by mothers are "recognised" by $M$ cells at the mucosal surface of the small intestine, where local lymphocytes are primed, whence they migrate via the lymphatic system to the breast. ${ }^{3}$ There plasma cells secrete specific IgA which acts to protect the mucosal surface of the gastrointestinal tract of the infant from those antigens. Human colostrum contains more than $1 \mathrm{~g} / 1$ of $\operatorname{IgA}$ and the fully breast fed infant ingests as much as 1 g of IgA each day. ${ }^{12}$

There have been a number of prospective studies of the changes in IgA concentrations of human milk throughout lactation, ${ }^{4-6}$ but none has measured interbreast variations in output, nor sequential changes throughout every month of lactation, and during each season of the year.

The aim of this study was to measure the concentrations of total IgA in the milk, secreted by both breasts, of a cohort of mothers throughout the first year of lactation and to quantify the intake of IgA by their infants during this time.

Subjects and methods

A prospective cohort study design was used. The project took place at the overseas research unit of the MRC Dunn Nutrition Unit in the village of Keneba in the Gambia. ${ }^{7}$ All the mothers in this village breast feed their infants for at least one year. The median age of the first introduction of non-milk, local weaning foods is 3 months.

Eighty one mothers were eligible for enrolment to the study. Two mothers declined to participate and 14 dropped out because of illness or absence from the village. Sixty five Gambian mothers were studied monthly during the first year of lactation. A $5 \mathrm{ml}$ volume of milk was collected before each feed from both breasts by manual expression and samples were stored at $-20^{\circ} \mathrm{C}$ and transported to the UK, packed in solid carbon dioxide, where analyses were performed.

Twelve hour weighed milk intakes (0700 to $1900 \mathrm{~h}$ ) were measured for all 65 mothers on five occasions during the year at 9, 17, 27, 39, and 51 weeks postpartum. The volume of milk ingested by each infant was measured by weighing the infant before and after each feed using an electronic balance accurate to $1 \mathrm{~g}$ (Mettler, Switzerland).

Milk samples were assayed for total IgA using an enzyme linked immunosorbent assay (ELISA) on 96 well polystyrene microtitre 


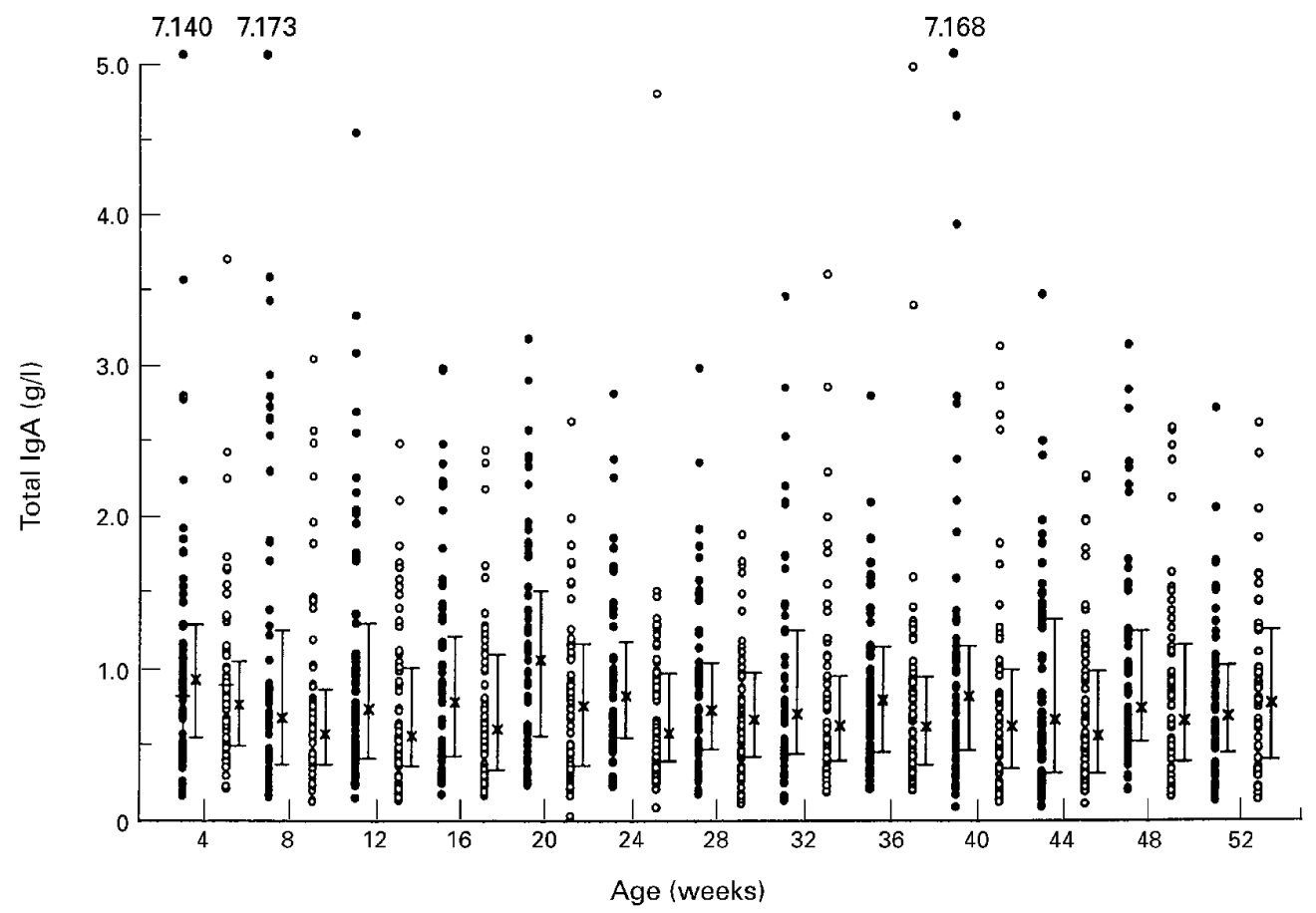

Figure 1 Total IgA concentrations in milk samples obtained from the left (closed symbols) and right (open symbols) breasts of mothers during the first year of lactation. The median and interquartile ranges are shown.

plates (Immulon 4, Dynax, Billinghurst) coated with a human colostral standard (Sigma, Poole). The plates were coated and left overnight at $4^{\circ} \mathrm{C}$ with $100 \mu \mathrm{l} / \mathrm{well}(4 \mu \mathrm{g} / \mathrm{ml})$ goat antihuman IgA (Sigma) diluted in $0.1 \mathrm{~mol} / 1$ carbonate buffer ( $\mathrm{pH}$ 9.6). After three washes with $\mathrm{pH} 7.3$ phosphate buffered saline (PBS) containing $0.05 \%$ Tween, the plates were blocked with $1 \% \mathrm{w} / \mathrm{v}$ bovine serum albumin (BSA) (Sigma) in PBS for one hour at room temperature. After a further three washes the milk samples and colostrum standards were diluted in $1 \% \mathrm{w} / \mathrm{v}$ BSA/PBS and loaded onto
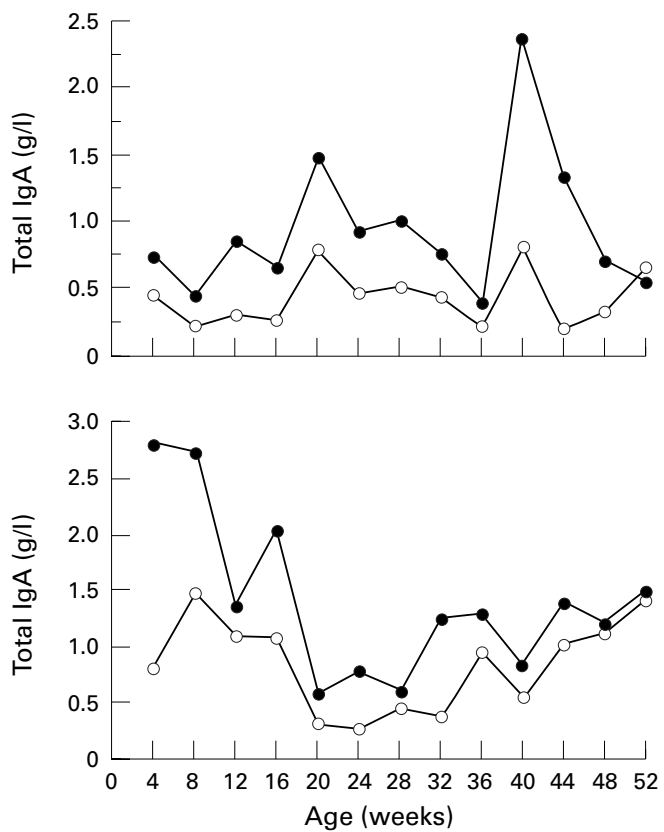

the plate at $100 \mu \mathrm{l} /$ well and incubated overnight at $4^{\circ} \mathrm{C}$. After washing with PBS/Tween, 100 $\mu 1 /$ well of horseradish peroxidase conjugated goat antihuman IgA (Sigma) (diluted 1:12000 in $1 \% \mathrm{w} / \mathrm{v} \mathrm{BSA} / \mathrm{PBS}$ ) were added and the plates were incubated at room temperature for two hours. Finally, the plates were washed a further three times with PBS/Tween and $100 \mu \mathrm{l}$ of 0.4 $\mathrm{mg} / \mathrm{ml}$ freshly prepared $O$-phenylenediamine dihydrochloride dissolved in $0.05 \mathrm{~mol} / 1$ phosphate-citrate buffer ( $\mathrm{pH}$ 5.0) containing $0.4 \mu \mathrm{l} / \mathrm{ml}$ hydrogen peroxide $(0.04 \%)$ was added. The reaction was stopped after 20 min-
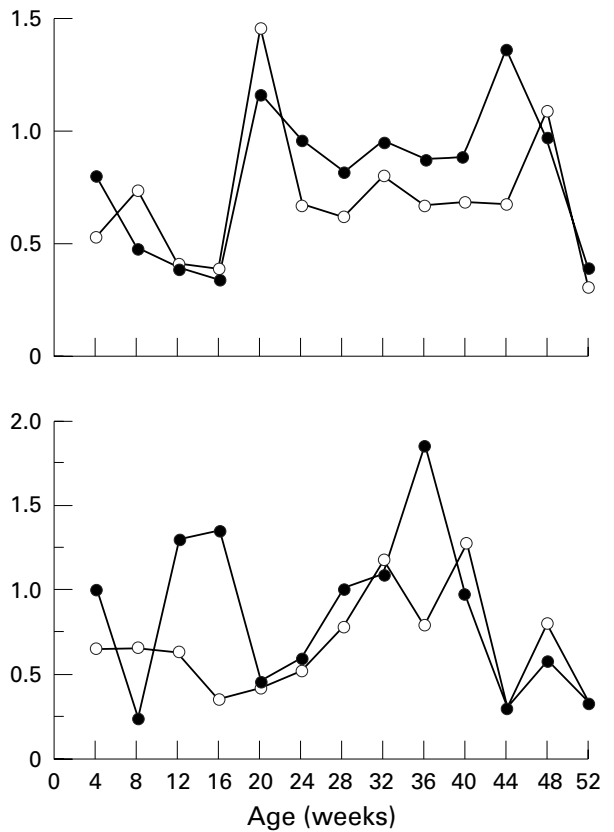

Figure 2 Total IgA concentration of milk obtained from the left (closed symbols) and right (open symbols) breasts from four mothers, showing parallel changes during the first year of lactation. 
Table 1 Changes in milk ingested (mean, SD), total IgA concentration (median, interquartile range), and total IgA ingested/12 hours (median, interquartile range) for all 65 mother-infant pairs

\begin{tabular}{llllll}
\hline & \multicolumn{2}{l}{ Age (weeks) } & & & \\
\cline { 2 - 6 } & $8-9$ & $16-17$ & $27-28$ & $39-40$ & $51-52$ \\
\hline Milk ingested (g/12 hours) & $376(98)$ & $358(96)$ & $334(96)$ & $343(106)$ & $312(94)$ \\
IgA concentration (g/l) & 0.625 & 0.666 & 0.680 & 0.715 & 0.746 \\
IgA ingested (mg/12 hours) & $(0.376-0.959)$ & $(0.399-1.125)$ & $(0.451-1.008)$ & $(0.359-1.063)$ & $(0.408-1.067)$ \\
& $242(172-392)$ & $279(151-363)$ & $221(157-333)$ & $258(138-393)$ & $208(151-336)$ \\
\hline
\end{tabular}

utes by adding $1 \mathrm{~N}$ sulphuric acid and the absorbance was determined at $490 \mathrm{~nm}$ using a Dynatech MR5000 ELISA plate reader (Dynax).

Changes in IgA concentration over time, between each breast, and in relation to season, maternal age, and parity were analysed using appropriate parametric and non-parametric tests of statistical significance. The study was undertaken with the approval of the joint MRC-Gambian Government ethical committee and was performed with the informed consent of the mothers and a meeting of the village elders.

\section{Results}

A total of 1590 milk samples was assayed (798 from the right breast and 792 from the left breast). The median (interquartile range) concentration of IgA from all samples was 0.708 $(0.422-1.105) \mathrm{g} / \mathrm{l}$. There was a significant difference in the median (interquartile range) IgA concentration of milk obtained from the left breast, which was $0.785(0.458-1.247) \mathrm{g} / 1$ and that from the right breast, which was 0.645 (0.388-1.011) g/l ( $\mathrm{p}<0.0001)$ (fig 1).

There was no significant change in the median IgA concentrations from the whole population over time during the first year (fig 1). There were, however, significant degrees of variation within individual mothers, with a close concordance of IgA concentrations between the two breasts, with "tracking" of the output of both breasts. Figure 2 shows four examples of these parallel changes in IgA concentration in milk obtained from the two breasts.

Table 1 gives the results for the five periods when milk intakes were measured. The mean (SD) weight of milk ingested in 12 hours by infants ranged between 376 (98) g (at 8-9 weeks) and 312 (94) g (at 51-52 weeks). The median (interquartile range) of IgA concentrations in milk ranged from $0.625(0.376-0.959)$ $\mathrm{g} / 1$ (at 8-9 weeks) to $0.746(0.408-1.067) \mathrm{g} / 1$ (at 51-52 weeks). The median (interquartile range) weight of IgA ingested in 12 hours by infants ranged from a maximum of 279 (151363) $\mathrm{mg}$ at $16-17$ weeks to a minimum of 208 (151-336) $\mathrm{mg}$ at 51-52 weeks. There was no significant change in weight of IgA ingested with advancing age. There was no significant correlation between the weight of milk ingested and IgA concentrations at any age except at 9 weeks, when it was $\mathrm{p}<0.002$.

The results from each mother were averaged over the year and there was a significant $(\mathrm{p}<$ 0.01 ) negative correlation between maternal age and parity, and the weight of milk ingested by their infants, but the correlations with the concentration of milk $\operatorname{IgA}$ and weight of $\operatorname{IgA}$ ingested were barely significant.

During the two dry seasons (December to May) the median (interquartile range) milk IgA concentration was significantly higher $(\mathrm{p}<$ $0.0001)$ at $0.853(0.571-1.254) \mathrm{g} / 1$ than during the three rainy seasons (June to November), when it was $0.518(0.311-0.909) \mathrm{g} / \mathrm{l}$. The weight of milk ingested was less in the wet season (330 g/12 hours) than in the dry season (median $361 \mathrm{~g} / 12 \mathrm{~h})(\mathrm{p}<0.03)$. The weight of IgA ingested was significantly higher in the dry seasons $(\mathrm{p}<0.0001)(310(212-418) \mathrm{mg} / 12$ hours) than during the rainy seasons (175 (118-266) $\mathrm{mg} / 12$ hours) (fig 3 ).

\section{Discussion}

We have shown that mothers maintain a steady output of IgA throughout the first year of lactation, that there is a difference in the concentration of IgA secreted by each breast, and there is a variation throughout the year according to season. The seasonal changes are due more to fluctuations in milk IgA concentrations than the weights of milk ingested. These findings confirm and extend those of other studies of lactating mothers in both the developing and developed world, ${ }^{4-6}$ and underline the potential value of prolonged breast feeding in infancy. Human milk has been shown to confer protection against several enteric and respiratory infections, ${ }^{28}$ and in circumstances of poor hygiene and high risk of infection it is likely to be of significant importance to the suckling infant.

IgA acts at the mucosal surface of the gastrointestinal tract to protect against potentially harmful microbial and food antigens. Although the infants continued to ingest a constant amount of IgA each day, the amount relative to body weight decreased. The length of the small intestine increases by $56 \%$ during the first year of postnatal life, in parallel with an increase in body weight of $55 \%$ and length of $50 \% .^{9}$ IgA survives passage through the gastrointestinal tract ${ }^{10}$ and its detection in the faeces of breast fed infants throughout the first year suggests that the amounts ingested remain sufficient to provide mucosal protection in spite of the increasing surface area of the gastrointestinal tract.

The amount of IgA ingested by the infants was dependent on both the weight of milk consumed and the concentration of IgA within it. For the whole cohort IgA concentrations did not change significantly between 8 and 52 weeks (fig 1), but seasonality affected the intake through an effect largely on the $\operatorname{IgA}$ 


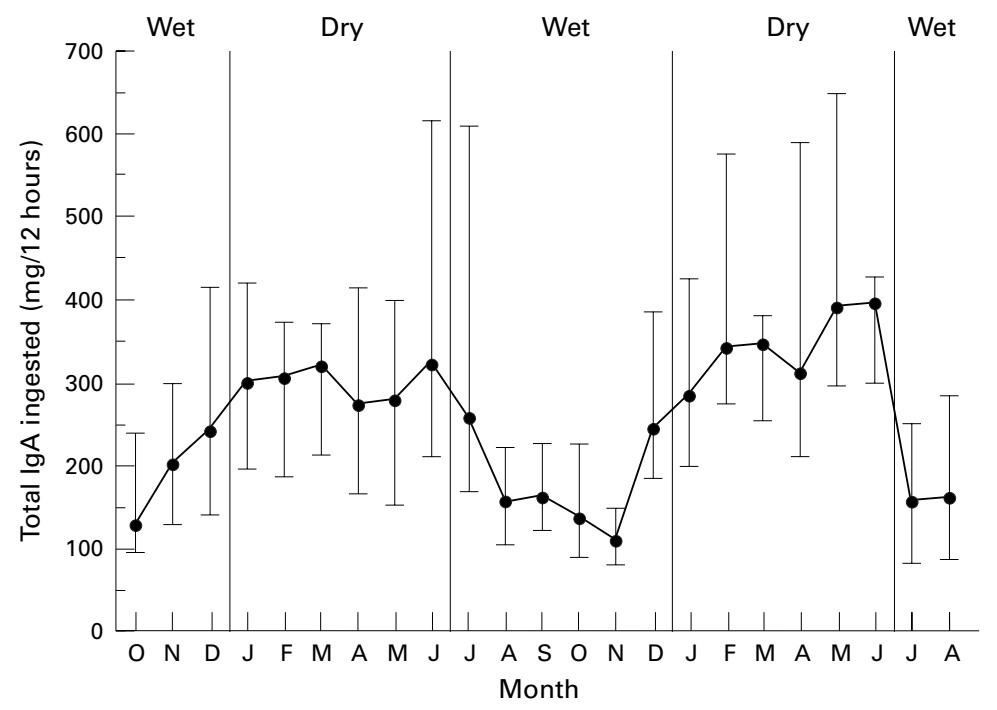

Figure 3 Total IgA ingested in 12 hours throughout the year showing seasonal changes. Median and interquartile ranges are shown.

concentration, resulting in an almost doubling of the IgA ingested by infants during the dry season (fig 3). The Gambian dry season is a time of plentiful food, good maternal nutritional status, and low prevalence of infection. In contrast, food stocks are depleted, nutritional status declines, and infection is common in the wet season. The influence of season on milk IgA concentrations and output has been described previously, but it is not thought to be due to variations in the prevalence of infectious diseases. ${ }^{11}$ Lower parity and maternal age were both associated with higher concentrations of IgA in milk, as described previously in the Gambia, ${ }^{12}$ but in a study in Zaire milk IgA concentrations were highest in multiparous women. ${ }^{6}$

The parallel changes in concentrations of IgA in milk obtained from each breast suggests that the synthesis or secretion of IgA is controlled above the level of the breast. This hypothesis is strengthened by our observation of seasonal effects in which changes in milk output and IgA concentrations parallel changes in maternal nutritional status. ${ }^{11}$ These have been well described previously during pregnancy in the same population, albeit in smaller numbers of mothers. ${ }^{13}$ Regulation must, however, be by factors other than maternal nutrition alone, as dietary supplementation has been shown not to abolish variations. ${ }^{5}$ Unilateral breast dysfunction can affect milk composition, but the average milk output is not usually compromised. ${ }^{14}$

The method used to measure milk intakes has been used for many years in Keneba ${ }^{511} 13$ and its reliability has been validated using isotopic analysis. ${ }^{15}$ There appeared to be no change in milk IgA concentrations in response to complementary feeding. We have previously shown $^{16}$ that the introduction of a weaning (non-milk) diet is associated with a transient decrease in breast milk output, but that this is not long lasting.

The differences in IgA concentrations in milk obtained from the two breasts may be

\section{Key messages}

- Human milk is rich in protective proteins, including IgA, which plays a part in the prevention of microbial infection in suckling infants

- IgA secretion is maintained at around 0.5 g/day by Gambian mothers throughout the first year of lactation

- There is a negative correlation between maternal age and parity, and weight of milk ingested by infants

- During the dry season, when food is most plentiful, milk IgA concentrations are higher than during the rainy season, when food is scarcer

- There is a close concordance of milk IgA concentrations between the two breasts, with "tracking" of output of the left and right breasts, suggesting control of secretion above the level of the mammary gland

related to the tradition of starting infant feeding on the right side. In 19 mothers in whom suckling was closely observed, 18 offered their infants the right breast first. In four mothers, who were studied at 48 weeks of lactation, the mean milk intake from the right breast was $244 \mathrm{~g} / 12$ hours, and from the left breast $84 \mathrm{~g} / 12$ hours. There was no significant difference in the time infants were suckled on each side (29 minutes on the right and 27 minutes on the left). It is therefore possible that the larger volumes of milk secreted by the right breast could, through a dilutional effect, account for the smaller concentrations of $\operatorname{IgA}$ in milk from that side. We found no significant correlation between milk volumes and IgA concentrations, however, except at 9 weeks of age.

Breast milk not only makes a major contribution to the nutrition of infants, but also provides a range of non-nutritional, bioactive factors, ${ }^{17}$ including immunoproteins. ${ }^{1}$ In conditions where infectious disease is common, and where weaning foods may be suboptimal, ${ }^{18}$ mothers can provide their infants with quantities of $\operatorname{IgA}$ in milk that are likely to play a significant part in improving their health.

We thank Dorothy Stirling, Ann Prentice, Esther Oostenveld, Momodou Darboe, Baba Jobarteh, Mustapha Sanyang, Lamin Sanyang, Mustapha Sise, and Jean Hyslop for their help with this project, and the Thrasher Research Fund and Bristol-Myers Research Foundation for their support.

1 Wold AE, Hanson LÅ. Defense factors in human milk. Curr Opin Gastroenterol 1994;10:652-8.

2 Hanson LÅ, Hahn-Zoric M, Berndes $M$, et al. Breast feeding: overview and breast milk immunology. Acta Paediatr fpn 1994;36:557-61.

3 Kleinman RE, Walker WA. The enteromammary immune system. An important new concept in breast milk host defence. Dig Dis Sci 1979;24:876-82.

4 Goldman AS, Garza C, Johnson CA, et al. Immunologic factors in human milk during the first year of lactation. $\mathcal{F}$ Pediatr 1982;100:563-7.

5 Prentice A, Prentice AM, Cole TJ, et al. Breast-milk antimicrobial factors of rural Gambian mothers. 1. Influence of crobial factors of rural Gambian mothers. 1. Influence of
stage of lactation and maternal plane of nutrition. Acta stage of lactation and maternal

6 Hennart PF, Brasseur DJ, Delogne-Desnoeck JB, et al. Lysozyme, lactoferrin, and secretory immunoglobulin A content in breast milk: influence of duration of lactation, 
nutrition status, prolactin status, and parity of mothers. $A m$ F Clin Nutr 1991;53:32-9.

7 Weaver LT, Beckerleg S. Is health a sustainable state? A village study in the Gambia. Lancet 1993;341:1327-30.

8 Howie PW, Forsyth JS, Ogston SA, et al. Protective effect of breast feeding against infection. BMF 1990;300:11-6.

9 Weaver LT, Austin S, Cole TJ. Small intestinal length: a factor essential for gut adaptation. Gut 1991;32:1321-3.

10 Prentice A, MacCarthy A, Stirling DM, et al. Breast-milk and lactoferrin survival in the gastrointestinal tract. Acto Paediatr Scand 1989;78:505-12.

11 Prentice A, Watkinson M, Prentice AM, et al. Breast-milk antimicrobial factors of rural Gambian mothers. II. Influence of season and prevalence of infection. Acta Paediatr Scand 1984;73:803-9.

12 Prentice A, Prentice AM, Cole TJ, et al. Determinants of variations in breast milk protective factor concentrations of variations in breast milk protective factor concentrations
rural Gambian mothers. Arch Dis Child 1983;58:518-22.
13 Prentice AM. Variations in maternal dietary intake, birthweight and breast-milk output in the Gambia. In: Aebi $\mathrm{H}$, Whitehead RG, eds. Maternal nutrition duri
and lactation. Lausanne: Nestle, 1979:167-83.

14 Prentice A, Prentice AM. Unilateral breast dysfunction in Prentice A, Prentice AM. Unilateral breast dysfunction in
lactating Gambian women. Ann Trop Paediatr 1984;4:1923.

5 Coward WA. Measuring milk intake in breast-fed babies. $\mathcal{F}$ Pediatr Gastroenterol Nutr 1984;3:275-9.

16 Downes RM, Prentice AM, Coward WA, et al. Effect of weaning foods on milk intake in Gambian infants. Proc Nutr Soc 1992;51:78A

17 Weaver LT. Breast and gut: the relationship between lactating mammary function and neonatal gastrointestinal function. Proc Nutr Soc 1992;51:155-63.

18 Weaver LT. Feeding the weanling in the developing world: problems and solutions. Int 7 Food Sci Nutr 1994;45: problems
$127-34$. 